\title{
The effects of relative gain and age on peripheral blood mononuclear cell mitochondrial enzyme activity in preweaned Holstein and Jersey calves
}

\author{
A. M. Niesen and H. A. Rossow* \\ Population Health and Reproduction, University of California, Davis 95616
}

\begin{abstract}
Mitochondria are central to metabolism, nutrition, and health, but many factors can influence their efficiency. The objectives of this study were to determine if the mitochondrial enzyme activities of citrate synthase, complex I, complex IV, and complex V from peripheral blood mononuclear cells in Holstein and Jersey dairy calves were affected by age or relative gain as a percent of initial weight. Twenty-three Holstein and 23 Jersey heifer calves were enrolled between 3 and $6 \mathrm{~d}$ of age and whole blood samples were collected via jugular venipuncture at 1, 2, and 8 wk of age. Crude mitochondrial extracts were obtained from the peripheral blood mononuclear cell fraction at each time point and subsequently assayed for enzymatic activity. Age-dependent changes in activity were observed in complex $\mathrm{V}$ for both breeds. In Jersey calves complex IV and citrate synthase activity differed with age. Complex I activity was greater for high relative gain Jerseys and tended to be greater for high relative gain Holstein calves. Holstein calves had greater incidence of scours compared with Jersey calves, and in both breeds scouring calves exhibited greater complex $\mathrm{V}$ activity compared with those without scours. These data suggest that age and immune challenge in the form of scours affect mitochondrial complex V activity. Additionally, complex I activity may serve as a marker for calf growth potential because it was influenced by relative gain and not age. Key words: mitochondrial enzyme activity, respiratory complex enzyme activity, mitochondrial function, dairy calf gain, peripheral blood mononuclear cell
\end{abstract}

\section{INTRODUCTION}

Raising a replacement heifer to productive age is one of the largest costs for dairy producers (Hadley et al., 2006) and has been predicted to be as high as $20 \%$ of the costs associated with dairy production (Lehenbauer

Received May 21, 2018.

Accepted September 28, 2018.

*Corresponding author: Heidi.Rossow@gmail.com and Oltjen, 1998) or $\$ 1,200$ to $\$ 1,600$ per heifer (Tozer and Huffaker, 1999; Karzes, 2005). In addition to the large expense of rearing heifers, producers can expect high prewean calf mortality. Hadley et al. (2006) and Cooke et al. (2013) estimated that $13 \%$ of live-born heifer calves failed to reach first calving and $26 \%$ of cows were culled after their first lactation. Heifers can exit the herd due to poor growth, disease, lameness, reproductive failure, low production, or death (Roberts et al., 2012). Therefore, culling strategies that could identify heifers prone to premature exit from a herd would improve the economic and environmental costs associated with dairy production. Mitochondrial variation and number have been shown to be important in milk yield (Brown et al., 1988; Alex et al., 2015) and reproduction in cows (Ferreira et al., 2016). Nunnari and Suomalainen (2012) reported the ability of mitochondria to act as metabolic signaling centers and showed their dysfunction influences ovarian function, nutrient response, metabolic syndromes, neurologic conditions, and a multitude of disease states across species. Previous studies (Bell et al., 1985; Brown et al., 1988) suggested that lactation performance could be estimated more precisely considering the effects of maternal cytoplasmic inheritance. Additionally, Brown et al. (1988) suggested that evaluating mitochondria in young stock could predict future performance of cows and their progeny. Because mitochondria influence both health and production, methods of evaluating mitochondrial dysfunction could serve as both an indicator of future lactation performance and heifer survivability.

In humans, mitochondrial respiratory chain (RC) deficiencies can be evaluated using functional (i.e., oxygen consumption, substrate oxidation) or enzymatic approaches (Kirby et al., 2007). Because RC complexes are dually coded for by mitochondrial and nuclear DNA and the knowledge of underlying disease-causing mutations is limited, deficiencies are often diagnosed utilizing an enzymatic approach. The nearly ubiquitous presence of mitochondria across cell types suggests that deficiencies in the RC complexes could negatively affect any organ or tissue (Rustin et al., 1994) and result in impaired enzymatic activity. Enzymatic assays of the 
RC complexes I, II, III, IV, and citrate synthase (CS) isolated from liver, heart, muscle, and cultured cells are routinely used because they remain enzymatically stable after long-term storage at $-80^{\circ} \mathrm{C}$, allowing for higher throughput sample processing. Rustin et al. (1994) compared intact cell respiration and enzymatic activity from lymphocytes and isolated muscle mitochondria as well as the enzymatic activity of liver and heart homogenates and recommended the use of lymphocytes for initial characterization of deficiency due to the low level of invasiveness.

Assays of mitochondrial function could serve as a marker of future milk production and the survivability of a heifer. Establishing an index of how mitochondrial enzyme activity changes over time in dairy cattle could be key to the early identification and culling of cows based on metabolic potential. If heifers that were more prone to disease and metabolic syndromes could be identified before the costs of feeding them to a productive age were incurred, they could be culled early, saving the dairy industry in feed, labor, and environmental costs (manure and methane production). The objectives of this study were to determine if the mitochondrial enzyme activities of CS, complex I, complex $\mathrm{IV}$, and complex $\mathrm{V}$ from peripheral blood mononuclear cells (PBMC) in Holstein and Jersey dairy calves were affected by age or relative gain as a percent of initial weight and to collect initial data to form an index of optimal mitochondrial enzyme activity in preweaned dairy calves.

\section{MATERIALS AND METHODS}

\section{Calf Management and Methods}

This prospective, observational study was approved by the University of California, Davis Animal Care and Use Committee. Twenty-three Holstein and 23 Jersey heifer calves from a California commercial dairy were enrolled between December 2016 and February 2017 for the present study. Surviving animals will be followed and sampled through their first lactation; however, the present study focuses on the prewean period. Calves 3 to $6 \mathrm{~d}$ of age were enrolled with inclusion criteria being a respiratory score of 1 , general appearance score of 1 , and a scours score of 3 or less following the CalfTrack scoring system (Heinrichs et al., 2003). CalfTrack scores were recorded daily for 4 wk following enrollment. Blood samples were collected at 3 time points via jugular venipuncture. The first time point, 1 wk of age (TPT1), was selected because this is the earliest window samples could be obtained for mitochondrial enzyme analyses due to immature cell differentiation. The second time point, 2 wk of age (TPT2), was se- lected for the onset of immune challenge in the form of scours. Last, calves were sampled at 8 wk (TPT3), just before weaning. During the course of the study, 2 Holsteins and 1 Jersey calf died between TPT2 and TPT3, resulting in their data being dropped from analyses.

Immediately after birth, calves were housed in raised individual wooden hutches with concrete flush lanes beneath and ad libitum access to water. Hutches were arranged in groups of 3 and were fitted with retractable roofing. Calves were randomly organized in hutches by birth date. Jerseys were provided straw bedding and blankets and Holsteins were not. After the first month of life, Jersey calf blankets and straw bedding were removed. Neonates were fed approximately $2 \mathrm{~L}$ of colostrum twice within $2 \mathrm{~h}$ of birth. Calves less than 1 mo old were fed $1.9 \mathrm{~L}$ of milk replacer 3 times daily at 0500,1200 , and $1900 \mathrm{~h}$. Calves greater than $1 \mathrm{mo}$ old were fed $1.9 \mathrm{~L}$ of a blend of hospital milk and milk replacer twice daily at 0500 and $1900 \mathrm{~h}$. Calf starter feed was provided ad libitum starting at $3 \mathrm{~d}$ of age and fed once daily in the morning. Calves were weaned at approximately $60 \mathrm{~d}$ of age at the discretion of the calf manager.

\section{BW Measurements}

Calves were weighed at the beginning and end of the study (i.e., TPT1 and TPT3) to evaluate growth. The second time point (TPT2) was excluded from BW measurements because it was a time of immune challenge and posed a biosecurity risk from scouring calves. Weights were measured using a spring suspension scale attached to a tow hydraulic hitch-mounted truck crane (Northern Tool, Burnsville, MN) with modifications. Calves were harnessed and hydraulically lifted off the floor of the hutch. A handler inside the hutch ensured that calves were not resting on the paneling during measurements and that they were released from the lift safely. Gloves and boot covers were changed after weighing 3 calves and when changing rows to reduce the risk of spreading disease. Jersey calf blankets were assumed negligible in weight but BW were corrected for harness weight.

\section{Blood Collection and Hematology}

Two sets of whole blood samples (30 and $4 \mathrm{~mL}$ ) were obtained via jugular venipuncture into vacutainer tubes (BD Biosciences, San Jose, CA) containing K2 EDTA as an anticoagulant at each of the 3 time points and processed within $1 \mathrm{~h}$ of sample collection. Care was taken to collect samples as quickly as possible and ensure minimal stress to the calves. 
Well-mixed blood ( $4 \mathrm{~mL}$ ) from a $\mathrm{K}_{2}$ EDTA tube was used to determine white blood cell count [thousands $(\mathrm{K}) / \mu \mathrm{L}]$, red blood cell count $[\mathbf{R B C}$, millions $(\mathrm{M}) /$ $\mu \mathrm{L}]$, hemoglobin $(\mathrm{g} / \mathrm{dL})$, hematocrit $(\%)$, mean corpuscular volume (MCV, fL), red cell distribution width (RDW, \%), neutrophil $(\mathrm{K} / \mu \mathrm{L}, \%)$, lymphocyte $(\mathrm{K} /$ $\mu \mathrm{L}, \%)$, monocyte $(\mathrm{K} / \mu \mathrm{L}, \%)$, eosinophil $(\mathrm{K} / \mu \mathrm{L}, \%)$, and basophil $(\mathrm{K} / \mu \mathrm{L}, \%)$ yield using the Drew Scientific Hemavet 950 Hematology Analyzer System (Erba Diagnostics, Oxford, CT). Before evaluating samples, quality control samples were tested to ensure equipment was functioning within specification (Multi-Trol, Drew Scientific).

\section{PBMC Isolation}

Platelet-rich plasma (PRP) and buffy coat were separated from the remaining whole blood $(30 \mathrm{~mL})$ by centrifugation at $2,000 \times g$ for $20 \mathrm{~min}$ at $20^{\circ} \mathrm{C}$. Plasma total protein was determined from the PRP using a handheld clinical ATC refractometer (Index Instruments, Ramsey, UK) and the remaining PRP was discarded. The buffy coat was diluted (1:4) with autoMACS Rinsing Solution (PBS, pH 7.2, and $2 \mathrm{mM}$ EDTA, Miltenyi Biotec, Sunnyvale, CA) and applied to a Histopaque density gradient (specific gravity 1.077, Cat. \#10771, Sigma Chemical Co., St. Louis, MO) and centrifuged without application of the brake at 2,000 $\times g$ for 20 min at $20^{\circ} \mathrm{C}$. The PBMC were collected and pelleted at $300 \times g$ for $10 \mathrm{~min}$ at $20^{\circ} \mathrm{C}$ and washed with autoMACS Rinsing Solution 3 times. Before the second wash, red cell contaminants were lysed via osmotic shock using distilled water, vortexed, and immediately diluted with autoMACS Rinsing Solution. The washed $\mathrm{PBMC}$ were then pelleted by centrifugation at $300 \times g$ for $10 \mathrm{~min}$ at $4^{\circ} \mathrm{C}$ and the supernatant was discarded. All subsequent steps used kits from Abcam (Cambridge, MA) and followed the manufacturer's instructions with modifications listed.

\section{Mitochondrial Isolation and Protein Quantification}

Mitochondria were extracted from PBMC using the Mitochondria Isolation Kit for Cultured Cells (ab110170, Abcam). Lysate protein concentration from PBMC was measured by BCA assay (ab102536, Abcam) and pellets were frozen at $-80^{\circ} \mathrm{C}$ for $10 \mathrm{~min}$ to weaken cellular membranes, and then supplemented with $0.2 \mu \mathrm{L}$ of universal nuclease (PI88700, Fisher Scientific Co., Fair Lawn, NJ). Samples were resuspended to $5 \mathrm{mg} / \mathrm{mL}$ in reagent $\mathrm{A}$ followed by homogenization. The homogenate was centrifuged at $1,000 \times g$ for 10 min. The resulting supernatant was saved and the pellet was resuspended in reagent B. Homogenization and spin steps were repeated once and the supernatants were combined and further centrifuged at 12,000 $\times \mathrm{g}$ for $15 \mathrm{~min}$ at $4^{\circ} \mathrm{C}$. The supernatant was discarded and the resulting crude mitochondrial pellet was dissolved in reagent $\mathrm{C}$ supplemented with protease inhibitor (ab201111, Abcam), aliquoted, and stored at $-80^{\circ} \mathrm{C}$. The crude mitochondrial protein concentration of 1 aliquot per sample was measured by BCA assay and used to correct the final mitochondrial enzyme activities (ab102536, Abcam).

\section{Measurement of Mitochondrial Complex I, Complex IV, Complex V, and CS Enzyme Activities}

All mitochondrial enzyme activities were measured using crude mitochondrial extracts. Microplates were incubated for $3 \mathrm{~h}$ at room temperature before the collection of absorbance data using a VersaMax tunable microplate reader (Molecular Devices, Sunnyvale, CA) in kinetic mode. Before evaluating samples, a calibration test plate (Bio-Tek Instruments Inc., Winooski, VT) was used to ensure the spectrophotometer was within specification. All enzymatic assays were performed the day after blood sample collection and mitochondria isolation. All assay kits were from the same manufacturer lot, were bovine species reactive, and the intraassay coefficients of variation for all kits were less than $3 \%$. Assay sensitivity data where appropriate can be found in the manufacturer's protocol.

Complex I (EC 1.6.5.3) Enzyme Activity Microplate Assay Kit (ab109721, Abcam) was used to determine the activity of complex I via immunocapture and spectrophotometric analysis. In short, activity was determined by an increase in absorbance at $450 \mathrm{~nm}$ following the oxidation of NADH to NAD+ and the simultaneous reduction of dye. Kinetic readings were measured at room temperature, $450 \mathrm{~nm}$, and 20-s intervals for 30 min with shaking between readings. Interassay coefficient of variation of this kit was less than $15 \%$.

Complex IV (EC 1.9.3.1) activity was measured using the Complex IV Human Enzyme Activity Microplate Assay Kit (ab109909, Abcam). Complex IV was immunocaptured and activity was determined by decreased absorbance at $550 \mathrm{~nm}$ resulting from the oxidation of reduced cytochrome c. Kinetic readings were measured at $30^{\circ} \mathrm{C}$ at 3 -min intervals for 60 min without shaking between readings. Interassay coefficient of variation of this kit was less than $7 \%$.

Complex V (EC 3.6.3.14) enzyme activity was determined using the ATP Synthase Enzyme Activity Microplate Assay Kit (ab109714, Abcam). The hydrolysis of ATP to ADP, facilitated by immunocaptured ATP-Synthase, was coupled to the oxidation of NADH to NAD+ resulting in reduced absorbance at $340 \mathrm{~nm}$. 
Kinetic readings were measured at $30^{\circ} \mathrm{C}$ at 1 -min intervals for $60 \mathrm{~min}$ without shaking between readings. Interassay coefficient of variation of this kit was less than $13 \%$.

The activity of CS (EC 4.1.3.7) was measured spectrophotometrically by increased absorbance at 412 $\mathrm{nm}$ via the development of 1,3,5-trinitrobenzene from 5,5'-dithiobis-2-nitrobenzoic acid using the Citrate Synthase Activity Assay Kit (ab119692, Abcam). Kinetic readings were measured at room temperature at 20-s intervals for $15 \mathrm{~min}$ with shaking between readings. Interassay coefficient of variation of this kit was less than $8 \%$.

\section{Statistical Analysis}

Calf was the experimental unit of interest and enzyme activity was defined as the linear rate of change of the absorbance per minute per crude mitochondrial protein loaded into the well. Care was taken to only include pre-steady-state kinetic values. The slope for each sample was determined using the GLM procedure of SAS to regress optical density on time (v.9.4, SAS Institute Inc., Cary, NC) with outlier removal set at 2 standard deviations and final activities corrected by crude mitochondrial protein. The model used in analysis was $\mathrm{Y}_{\mathrm{OD}}=\beta_{0}+\beta_{1}$ Time $+\varepsilon$, in which $\mathrm{Y}_{\mathrm{OD}}=$ the optical density, $\beta_{0}=$ the y-intercept, $\beta_{1}=$ the regression coefficient of time, and $\varepsilon=$ the residual error.

The data were analyzed using the Mixed procedure of SAS (v.9.4, SAS Institute Inc.) with repeated measures by calf and time point as a random effect. The model used in the analysis was $\mathrm{Y}_{\text {bat }}=\mu+\mathrm{A}_{\mathrm{b}}+\mathrm{B}_{\mathrm{a}}+\mathrm{C}_{\mathrm{t}}+$ $\mathrm{e}_{\text {bat }}$, where $\mathrm{Y}_{\text {bat }}=$ the enzyme activity $(\mathrm{CS}$, complex I, complex IV, or complex V), $\mu=$ the overall mean, $A_{b}$ $=$ breed (Holstein or Jersey), $\mathrm{B}_{\mathrm{a}}=\mathrm{ADG}$ relative gain (high or low), $\mathrm{C}_{\mathrm{t}}=$ time point relative gain $(1,2$, or 3 ), and $\mathrm{e}_{\mathrm{bat}}=$ the residual error.

A $P$-value of 0.05 was used for the determination of statistical significance, and tendencies were $0.05<P$ $\leq 0.10$. All data were expressed as least squares means with standard error of the mean.

\section{RESULTS AND DISCUSSION}

\section{Changes in Hematology with Time Point and Immune Challenge}

Hematological data were collected at each time point to establish a profile of the developmental variability of blood parameters and identify markers of immune challenge in calves. Because analyses of mitochondrial enzyme activity were performed on PBMC, the hematological and immunological state of the calves could affect their activities. The normal hematological references ranges were preset on the Hemavet 950 Hematology Analyzer System, which does not have different ranges for calves versus adult cattle. Table 1 shows data for Holsteins and Table 2 for Jerseys.

During TPT1, the incidence of abnormal hematological parameters showed that both Holstein calves (Table 1) and Jersey calves (Table 2) were in early development and were not in an immune-challenged state. Calf hematological profiles with elevated neutrophils, low lymphocytes, and MCV (Tables 1 and 2) were in accordance with previous studies and reflected the immature state of blood cells. A high ratio of neutrophils to lymphocytes is common during a calf's first week of life (Adams et al., 1992; Benesi et al., 2012; Panousis et al., 2018). Low MCV during this time (1 wk of age) is well documented and represents the replacement of RBC containing fetal hemoglobin with smaller RBC containing hemoglobin A (Grimes et al., 1958; BrunHansen et al., 2006; Panousis et al., 2018). However, Holstein calves had a greater incidence of elevated neutrophils and low lymphocytes (Table 1) compared with Jersey calves where nearly all animals exhibited normal neutrophil and lymphocytes numbers (Table 2). Both groups of calves displayed low hemoglobin and decreased hematocrit, but Jersey calves had greater incidences than Holstein calves. Previous studies found similar results for calf red cell count and decreased hemoglobin and hematocrit during the first week of life (Kurz and Willett, 1991; Klinkon and Ježek, 2012). Three Holstein calves (14\%; Table 1) and 6 Jersey calves (29\%; Table 2) had low plasma total protein, which indicated incomplete passive transfer and could result in increased risk of disease, mortality, and lower growth rates in subsequent time points (Robison et al., 1988; Furman-Fratczak et al., 2011; MacFarlane et al., 2014). The high variability in the neonate calves' hematological profiles indicated that calves sampled during TPT1 may be too developmentally immature to identify RC deficiencies in PBMC mitochondrial enzyme activity.

The incidence of calves with abnormal hematological profiles increased during TPT2 and was indicative of an immune-challenged state. Fifteen Holstein calves (68\%; Table 1) and 8 Jersey calves (38\%; Table 2) experienced 2 or more scouring days during TPT2. The range of scours duration for Holsteins during TPT2 was 2 to $7 \mathrm{~d}$ with a mean of $2.5 \mathrm{~d}$ as identified by CalfTrack scoring. For Jerseys, the range of scours duration was 2 to $5 \mathrm{~d}$ with a mean of $3.6 \mathrm{~d}$ (Table 3 ). Scours is caused by a range of viruses, bacteria, and protozoa, which could affect both the hematological profile and mitochondrial metabolism in PBMC. Although some of the hematological parameters such as lymphocyte number, hemoglobin, and hematocrit levels shifted to- 

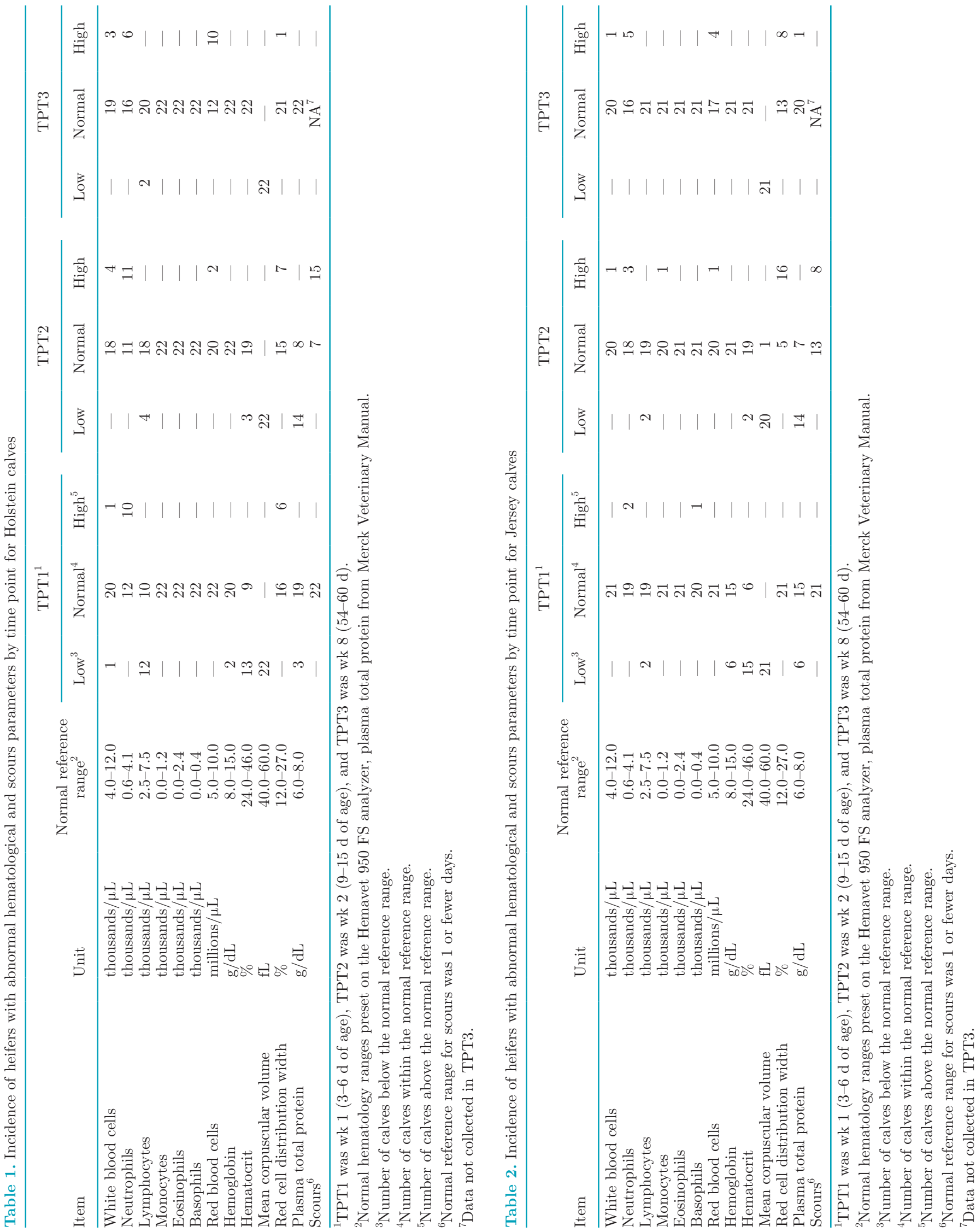
Table 3. Incidence of abnormal health events identified by CalfTrack scoring by breed ${ }^{1}$

\begin{tabular}{lccccccc}
\hline & \multicolumn{4}{c}{ Holstein } & & \multicolumn{3}{c}{ Jersey } \\
\cline { 2 - 4 } \cline { 6 - 8 } Item & $0-6 \mathrm{~d}$ & $7-15 \mathrm{~d}$ & $16 \leq \mathrm{d} \leq 30$ & & $0-6 \mathrm{~d}$ & $7-15 \mathrm{~d}$ & $16 \leq \mathrm{d} \leq 30$ \\
\hline Scours $^{2}$ & - & $15^{3}$ & - & & - & $8^{4}$ & - \\
Respiratory $^{5}$ & - & 2 & 18 & & - & 3 & 15 \\
General appearance $^{6}$ & - & 15 & 18 & & - & 8 & 15 \\
\hline
\end{tabular}

${ }^{1}$ CalfTrack scores (Heinrichs et al., 2003) are on a 1-5 scale with a score of 1 indicating healthy.

${ }^{2}$ Number of calves with scours scores $>3$ that occurred for 2 or more days were considered abnormal.

${ }^{3}$ The range of scours duration for Holsteins was 2 to $7 \mathrm{~d}$ with mean $=2.47 \mathrm{~d}$; scouring animals were supplied electrolytes and 8 animals were treated with Naxcel (ceftiofur sodium, Zoetis, Parsippany, NJ) and 1 treated with Baytril (enrofloxacin, Bayer Animal Health GmbH, Germany).

${ }^{4}$ The range of scours duration for Jerseys was 2 to $5 \mathrm{~d}$ with mean $=3.63 \mathrm{~d}$; scouring animals were supplied electrolytes and 5 animals were treated with only Naxcel and 1 animal was treated with Naxcel and Baytril.

${ }^{5}$ Number of calves with respiratory scores $\geq 3$ that occurred for 2 or more days were considered abnormal.

${ }^{6}$ Number of calves with general appearance scores $\geq 3$ that occurred for 2 or more days were considered abnormal.

ward normal, the number of calves with increased neutrophils, white blood cells, and monocytes increased. Mean corpuscular volume remained low in nearly all calves and red cell distribution (RDW), an indicator of the variability in size of $\mathrm{RBC}$, increased in both breeds (Tables 1 and 2). The elevated RDW in Holstein calves was only slightly increased compared with TPT1. However, Jersey calves, which did not have elevated RDW in TPT1, had 16 animals with high RDW at TPT2. Further, 15 Holstein calves (64\%; Table 1) and 14 Jersey calves (67\%; Table 2) had low plasma total protein, probably resulting from scours at this time point. Diarrhea decreases albumin levels and results in low plasma total protein and could be associated with elevated RDW and white blood cell counts in immunechallenged calves. Due to the increased incidence of calves with abnormal hematological profiles and scours, measurements of PBMC mitochondrial activity during TPT2 may reflect the effects of an immune-challenged state.

In TPT3, hematological profiles of Holsteins and Jerseys continued to shift toward normal ranges with the exception of low MCV in all calves and an increase in $\mathrm{RBC}$ production in 10 Holstein calves (45\%; Table 1) and 4 Jersey calves (19\%, Table 2). The majority of Holstein and Jersey calves did not have elevated RBC based on the Hemavet 950 Hematology Analyzer System reference range of 5 to $10 \mathrm{M} / \mu \mathrm{L}$. But Brun-Hansen et al. (2006) compared calf hematological parameters to adult reference ranges and reported that calves had elevated RBC from birth to $29 \mathrm{wk}$ based on a reference range of 4.6 to $6.9 \mathrm{M} / \mu \mathrm{L}$, which was generated from a sample of lactating Norwegian Red cows. Therefore, breed differences may exist in what is considered a normal RBC profile. In TPT3, the number of calves with high variability in RDW dropped from 7 Holstein calves in TPT1 to 1 calf in TPT3 (Table 1 ) and from 16 Jersey calves in TPT2 to 8 calves in TPT3 (Table 2 ), supporting a shift toward normal ranges as calves recovered from scours. The MCV remained low in nearly all calves across time points, indicating that the adult reference ranges of the Hemavet 950 Hematology Analyzer System may not be a reliable tool for evaluating calf MCV through the prewean period. Of all the time points observed, TPT3 was the most stable in calf health assessment based on hematological profiles and may be the ideal time to evaluate PBMC RC deficiencies.

\section{CS Activity}

Citrate synthase is the first enzyme in the tricarboxylic acid cycle. It is also correlated with mitochondrial content in skeletal muscle and is often used to normalize RC activities to mitochondrial content (Larsen et al., 2012). The relationship between PBMC mitochondrial enzyme activities, age, and relative gain are shown by breed in Table 4 . Because CS activity increased at TPT2 for Jerseys only (Table $4 ; P<0.05$ ), it is unknown if the increased CS activity resulted from an immune challenge, age-related changes, or an increase in mitochondrial content. We chose not to correct enzyme activities by CS activity because complex I, which has been shown to be correlated with mitochondrial content, did not peak at TPT2 for either breed. This suggests that increased CS activity did not result from an alteration to mitochondrial content (Table 4; Larsen et al., 2012). To evaluate the effects of immune challenge, the mitochondrial enzyme activities of animals with and without scours were compared by time point and breed (Table 5). No difference in CS activity was observed between Holsteins or Jerseys across all 3 time 
Table 4. Mitochondrial enzyme activities of peripheral blood mononuclear cells from Holstein and Jersey calves

\begin{tabular}{|c|c|c|c|c|c|c|}
\hline \multirow[b]{2}{*}{ Item } & \multirow[b]{2}{*}{$\mathrm{TPT}^{1}$} & \multirow[b]{2}{*}{ TPT2 } & \multirow[b]{2}{*}{ TPT3 } & \multirow[b]{2}{*}{ SEM } & \multicolumn{2}{|c|}{$P$-value } \\
\hline & & & & & Gain & $\mathrm{TPT}^{2}$ \\
\hline \multicolumn{7}{|l|}{ Enzyme (Holstein) } \\
\hline Citrate synthase 3 & 0.878 & 0.995 & 0.870 & 0.06 & $0.99^{4}$ & 0.89 \\
\hline Complex I & 0.080 & 0.081 & 0.079 & 0.01 & $0.08^{4}$ & 0.96 \\
\hline Complex IV & 0.183 & 0.209 & 0.217 & 0.02 & $0.57^{4}$ & 0.47 \\
\hline Complex V & $0.058^{\mathrm{b}}$ & $0.074^{\mathrm{a}}$ & $0.080^{\mathrm{a}}$ & 0.01 & $0.25^{4}$ & $<0.01$ \\
\hline \multicolumn{7}{|l|}{ Enzyme (Jersey) } \\
\hline Citrate synthase & $0.900^{\mathrm{b}}$ & $1.120^{\mathrm{a}}$ & $0.844^{\mathrm{b}}$ & 0.08 & $0.91^{5}$ & $<0.01$ \\
\hline Complex I & 0.093 & 0.087 & 0.081 & 0.01 & $0.04^{5}$ & 0.62 \\
\hline Complex IV & $0.187^{\mathrm{b}}$ & $0.244^{\mathrm{a}}$ & $0.188^{\mathrm{b}}$ & 0.09 & $0.78^{5}$ & 0.02 \\
\hline Complex V & $0.059^{\mathrm{b}}$ & $0.073^{\mathrm{a}}$ & $0.077^{\mathrm{a}}$ & 0.01 & $0.96^{5}$ & $<0.01$ \\
\hline
\end{tabular}

${ }_{\mathrm{a}, \mathrm{b}}$ Means within a row with different superscripts differ $(P<0.05)$.

${ }^{1}$ TPT1 was wk 1 (3-6 d of age), TPT2 was wk 2 (9-15 d of age), and TPT3 was wk 8 (54-60 d).

${ }^{2}$ Comparison of mitochondrial enzyme activities at different time points (TPT).

${ }^{3}$ Units of enzyme activity are milli-optical density units $(\mathrm{mOD}) / \mathrm{min}$ per $\mu \mathrm{g}$ of mitochondrial protein.

${ }^{4}$ Comparison of Holstein mitochondrial enzyme activities for low $(42.13 \%)$ and high $(100.14 \%)$ prewean relative gain as a percent of initial weight; calves with relative gain below average $(71.13 \%)$ were assigned to a low relative gain group and calves above the average were assigned to a high relative gain group. Low relative gain complex I activity was $0.076 \mathrm{mOD} / \mathrm{min}$ per $\mu \mathrm{g}$, and high relative gain complex I activity was $0.095 \mathrm{mOD} /$ $\min$ per $\mu \mathrm{g}$.

${ }^{5}$ Comparison of Jersey mitochondrial enzyme activities for low (66.84\%) and high (109.67\%) prewean relative gain as a percent of initial weight; calves with relative gain below average $(89.27 \%$ ) were assigned to a low relative gain group and calves above the average were assigned to a high relative gain group. Low relative gain complex I activity was $0.077 \mathrm{mOD} / \mathrm{min}$ per $\mu \mathrm{g}$, and high relative gain complex I activity was $0.095 \mathrm{mOD} /$ $\min$ per $\mu \mathrm{g}$.

points, indicating that the peak in CS activity at TPT2 observed in Jerseys (Table 4) was not the result of immune challenge, but reflected age-related changes.

\section{Complex I and Complex IV Activity}

Complex I and complex IV assist in the formation of the proton gradient that drives ATP production through complex V. Complex I activity did not change with age for either breed $(P>0.6$; Table 4$)$. When evaluating relative gain as a percent of initial weight, Jerseys had greater complex I activity for high compared with low gain calves. High gain Holsteins tended to have increased complex I activity compared with low gain Holstein calves $(P<0.08$; Table 4$)$. The mean relative gain of the Holstein high group was $100.14 \%$ of initial weight and the mean relative gain of the Holstein low group was $42.13 \%$ of initial weight, and these

Table 5. Mitochondrial enzyme activities of peripheral blood mononuclear cells from animals with and without scours by time point

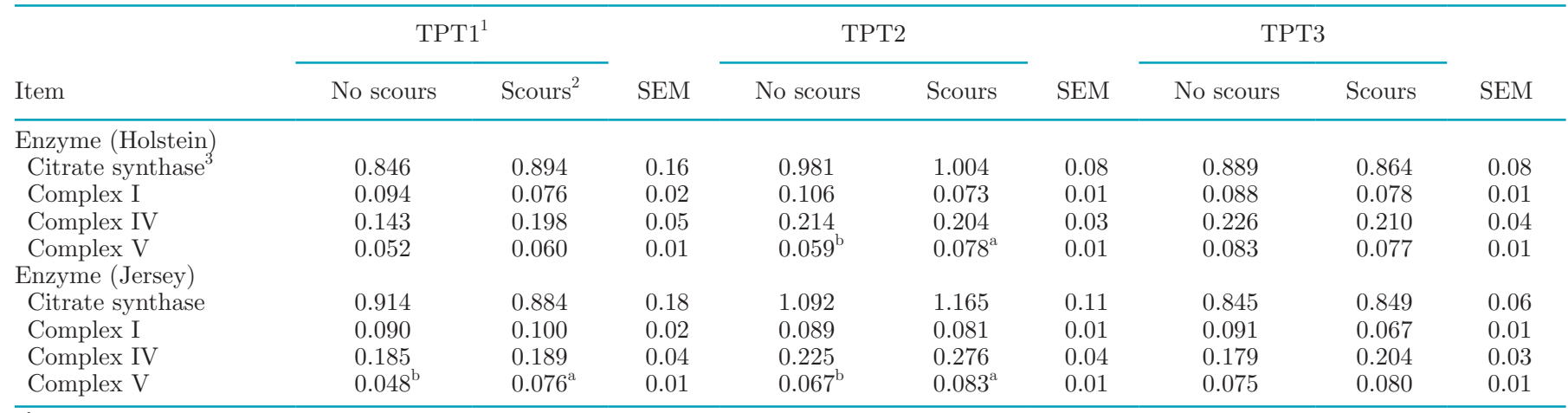

\footnotetext{
${ }^{\mathrm{a}, \mathrm{b}}$ Means within a row and time point with different superscripts differ $(P<0.05)$.
}

${ }^{1}$ TPT1 was wk 1 (3-6 d of age), TPT2 was wk 2 (9-15 d of age), and TPT3 was wk 8 (54-60 d).

${ }^{2}$ Scours was defined as greater than $1 \mathrm{~d}$ scouring, and scouring and nonscouring animals were identified in TPT2; additional group comparisons were made before scours onset and after recovery from scours, TPT1, and TPT3, respectively.

${ }^{3}$ Units of enzyme activity are milli-optical density units/min per $\mu \mathrm{g}$ of mitochondrial protein. 
gains corresponded with complex I enzyme activities of 0.095 and 0.076 milli-optical density units/min per $\mu \mathrm{g}$, respectively. The mean relative gain of the high group for Jerseys was $109.67 \%$ of initial weight and the mean relative gain of the low Jersey group was $66.84 \%$ of initial weight. These gains corresponded with complex I enzyme activities of 0.095 and 0.077 milli-optical density units/min per $\mu \mathrm{g}$, respectively. Complex I activity increased in response to increased metabolism to support protein synthesis in growing calves and may serve as a marker of calf growth potential.

Complex IV activity was not different by age or relative gain for Holsteins. Jerseys showed age-related changes but no gain effects (Table 4). The Holstein data are in apparent agreement with Chretien et al. (1998) where no changes in muscular complex IV activity in humans aged 0 to $3 \mathrm{yr}$ or 0 to $65 \mathrm{yr}$ were observed. But, Smeitink et al. (1989) compared human neonate skeletal muscle RC activity to adults and found that all activities were greater with age. Kwong and Sohal (2000) also evaluated enzyme activity in complexes I to IV in kidney, liver, heart, brain, and skeletal muscle in mice as they aged and observed age-related increases in complex IV activity in heart and skeletal tissue and no age-related changes in complex I. The increased complex IV activity for Jerseys at TPT2 (Table 4) does not appear to result from immune challenge. Jerseys with and without scours at TPT2 showed no difference in complex IV activity (Table 5), indicating that the effect is age related. The lack of age-related changes in complex I for both breeds and the lack of age-related changes in complex IV in Holsteins may result from the narrow window in which calves were sampled. This study evaluated calves over $2 \mathrm{mo}$, so extended agerelated changes in complex activities may not yet be evident. To date, no studies have evaluated age-related changes in complexes I and IV enzyme activities in calves and many of the data that exist in other species and tissues are contradictory. Differences in mitochondrial enzyme activities in dairy calves as they age, grow, and face varying physiological states may become more apparent as the animals are followed over a greater period of time.

\section{Complex V Activity}

Complex V is the source of ATP production and is driven by the proton gradient formed by earlier complexes (I and IV) in the electron transport chain. Complex V activity increased from TPT1 to TPT3 $(P$ $<0.01$, Table 4) for both breeds, indicating that agerelated changes occurred. Because complex $\mathrm{V}$ is the site of ATP production and growth requires an increased need for ATP, we hypothesized that complex V activity would be correlated with gain (Kilburn et al., 1969). However, complex $\mathrm{V}$ activity may be more related to increased nutrient processing due to increased feed intake as calves near weaning (i.e., not directly associated with a greater potential for growth as no differences between calves with high and low relative gain were observed; Table 4). Studies in beef cattle exploring oxygen consumption associated with proton-dependent and proton-independent respiration (proton leak) have demonstrated that RFI is generally not correlated with mitochondrial proton leak (Lancaster et al., 2014; Acetoze et al., 2015). Because proton leak results from a uncoupling of complexes I and IV from complex V, it follows that complex I activity reflects potential for growth and complex $\mathrm{V}$ reflects nutrient processing associated with feed intake to fulfill a need for ATP as calves age.

When comparing animals with and without scours across time points and by breed (Table 5) animals that scoured showed increased complex $\mathrm{V}$ activity in TPT2 $(P<0.05)$ and no difference in complex $\mathrm{V}$ activity at TPT3 as scouring events were isolated to TPT2. Additionally, Jersey calves showed increased complex $\mathrm{V}$ activity in TPT1, indicating that susceptible calves may exhibit increased complex $\mathrm{V}$ activity even before the onset of scours.

\section{CONCLUSIONS}

Peripheral blood mononuclear cell mitochondrial enzyme activities changed relative to age, immune challenge, and relative gain in preweaned dairy calves. Complex I activity increased in high relative gain Jerseys and tended to increase in high relative gain Holsteins. Therefore, complex I activity may serve as a marker for calf growth potential and could be used to evaluate varying management systems in relationship to calf growth. Complex $\mathrm{V}$ activity was greater in scouring animals for both Holsteins and Jerseys at TPT2. Additionally, Jersey calves showed increased complex V activity in TPT1, indicating that susceptible animals may exhibit increased complex $\mathrm{V}$ activity even before the onset of scours. If other complexes are to be used to predict calf performance based on $\mathrm{RC}$ enzyme activity, calves may be too young to sample in TPT1 due to high variability in the hematological and enzymatic profiles of preweaned calves.

\section{ACKNOWLEDGMENTS}

This work was supported by the USDA National Institute of Food and Agriculture, Hatch (Washington, 
DC)/Multistate project. Graduate student funding was provided by California Dairy Research Foundation (Davis).

\section{REFERENCES}

Acetoze, G., K. L. Weber, J. J. Ramsey, and H. A. Rossow. 2015. Relationship between liver mitochondrial respiration and proton leak kinetics in low and high RFI steers from two lineages of RFI Angus bulls. ISRN Vet. Sci. 2015:194014. https://doi.org/10.1155/ $2015 / 194014$.

Adams, R., F. Garry, B. Aldridge, M. Holland, and K. Odde. 1992. Hematologic values in newborn beef calves. Am. J. Vet. Res. 53:944-950.

Alex, A. P., J. L. Collier, D. L. Hadsell, and R. J. Collier. 2015. Milk yield differences between $1 \times$ and $4 \times$ milking are associated with changes in mammary mitochondrial number and milk protein gene expression, but not mammary cell apoptosis or SOCS gene expression. J. Dairy Sci. 98:4439-4448.

Bell, B. R., B. T. McDaniel, and O. W. Robison. 1985. Effects of cytoplasmic inheritance on production traits of dairy cattle. J. Dairy Sci. 68:2038-2051.

Benesi, F. J., C. Teixeira, M. L. Leal, J. A. Lisboa, R. Mirandola, C. L. Shecaira, and V. Gomes. 2012. Leukograms of healthy Holstein calves within the first month of life. Pesqui. Vet. Bras. 32:352-356.

Brown, D., S. DeNise, and R. McDaniel. 1988. Mitochondrial respiratory metabolism and performance of cattle. J. Anim. Sci. 66:13471354 .

Brun-Hansen, H. C., A. H. Kampen, and A. Lund. 2006. Hematologic values in calves during the first 6 months of life. Vet. Clin. Pathol. $35: 182-187$.

Chretien, D., J. Gallego, A. Barrientos, J. Casademont, F. Cardellach, A. Munnich, A. Rötig, and P. Rustin. 1998. Biochemical parameters for the diagnosis of mitochondrial respiratory chain deficiency in humans, and their lack of age-related changes. Biochem. J. 329:249-254.

Cooke, J., Z. Cheng, N. Bourne, and D. Wathes. 2013. Association between growth rates, age at first calving and subsequent fertility, milk production and survival in Holstein-Friesian heifers. Open J. Anim. Sci. 3:1-12. https://doi.org/10.4236/ojas.2013.31001.

Ferreira, R. M., M. R. Chiaratti, C. H. Macabelli, C. A. Rodrigues, M. L. Ferraz, Y. F. Watanabe, L. C. Smith, F. V. Meirelles, and P. S. Baruselli. 2016. The infertility of repeat-breeder cows during summer is associated with decreased mitochondrial DNA and increased expression of mitochondrial and apoptotic genes in oocytes. Biol. Reprod. 94:66.

Furman-Fratczak, K., A. Rzasa, and T. Stefaniak. 2011. The influence of colostral immunoglobulin concentration in heifer calves' serum on their health and growth. J. Dairy Sci. 94:5536-5543.

Grimes, R. M., C. W. Duncan, and C. A. Lassiter. 1958. Bovine fetal hemoglobin. I. postnatal persistence and relation to adult hemoglobins. J. Dairy Sci. 41:1527-1533.

Hadley, G. L., C. A. Wolf, and S. B. Harsh. 2006. Dairy cattle culling patterns, explanations, and implications. J. Dairy Sci. 89:22862296 .
Heinrichs, A., C. Jones, L. VanRoekel, and M. Fowler. 2003. Calf Track: A system of dairy calf workforce management, training, and evaluation and health evaluation. J. Dairy Sci. 86(Suppl 1):115.

Karzes, J. 2005. Dairy replacement programs: Costs and analysis. Proc. from Dairy Calves and Heifers, Integrating Biology and Management. NRAES 175:10-23.

Kilburn, D., M. Lilly, and F. Webb. 1969. The energetics of mammalian cell growth. J. Cell Sci. 4:645-654.

Kirby, D. M., D. R. Thorburn, D. M. Turnbull, and R. W. Taylor 2007. Biochemical assays of respiratory chain complex activity. Methods Cell Biol. 80:93-119.

Klinkon, M., and J. Ježek. 2012. Values of blood variables in calves. Pages 301-320 in A Bird's-Eye View of Veterinary Medicine. Intech, London, United Kingdom.

Kurz, M. M., and L. B. Willett. 1991. Carbohydrate, enzyme, and hematology dynamics in newborn calves. J. Dairy Sci. 74:2109-2118.

Kwong, L. K., and R. S. Sohal. 2000. Age-related changes in activities of mitochondrial electron transport complexes in various tissues of the mouse. Arch. Biochem. Biophys. 373:16-22.

Lancaster, P. G. Carstens, J. Michal, K. Brennan, K. Johnson, and M. Davis. 2014. Relationships between residual feed intake and hepatic mitochondrial function in growing beef cattle. J. Anim. Sci. 92:3134-3141.

Larsen, S., J. Nielsen, C. N. Hansen, L. B. Nielsen, F. Wibrand, N. Stride, H. D. Schroder, R. Boushel, J. W. Helge, and F. Dela. 2012. Biomarkers of mitochondrial content in skeletal muscle of healthy young human subjects. J. Physiol. 590:3349-3360.

Lehenbauer, T. W., and J. W. Oltjen. 1998. Dairy cow culling strategies: Making economical culling decisions. J. Dairy Sci. 81:264-271.

MacFarlane, J., D. Grove-White, M. Royal, and R. Smith. 2014. Use of plasma samples to assess passive transfer in calves using refractometry: Comparison with serum and clinical cut-off point. Vet. Rec. 174:303.

Nunnari, J., and A. Suomalainen. 2012. Mitochondria: In sickness and in health. Cell 148:1145-1159.

Panousis, N., N. Siachos, G. Kitkas, E. Kalaitzakis, M. Kritsepi-Konstantinou, and G. E. Valergakis. 2018. Hematology reference intervals for neonatal Holstein calves. Res. Vet. Sci. 118:1-10.

Roberts, T., N. Chapinal, S. J. LeBlanc, D. F. Kelton, J. Dubuc, and T. F. Duffield. 2012. Metabolic parameters in transition cows as indicators for early-lactation culling risk. J. Dairy Sci. 95:30573063

Robison, J. D., G. H. Stott, and S. K. DeNise. 1988. Effects of passive immunity on growth and survival in the dairy heifer. J. Dairy Sci. $71: 1283-1287$.

Rustin, P., D. Chretien, T. Bourgeron, B. Gerard, A. Rötig, J. Saudubray, and A. Munnich. 1994. Biochemical and molecular investigations in respiratory chain deficiencies. Clin. Chim. Acta 228:35-51.

Smeitink, J., R. Sengers, J. Trijbels, W. Ruitenbeek, O. Daniels, A Stadhouders, and M. Kock-Jansen. 1989. Fatal neonatal cardiomyopathy associated with cataract and mitochondrial myopathy. Eur. J. Pediatr. 148:656-659.

Tozer, P., and R. Huffaker. 1999. Mathematical equations to describe lactation curves for Holstein-Friesian cows in New South Wales. Aust. J. Agric. Res. 50:431-434. 